\title{
Structural safety during construction
}

Karel TERWEL

Lecturer and researcher

structural design \& safety

Delft University of

Technology

Delft, the Netherlands

k.c.terwel@tudelft.nl
Martijn MUD

Operational director

RPS Advies

Delft, the Netherlands

martijn.mud@rps.nl
Adri FRIJTERS

Policy advisor Occupational

Safety \& Safety

Management Systems

Arbouw

Harderwijk, the Netherlands

frijters@arbouw.nl

\section{Summary}

Structural safety during construction is a main concern for the building industry. Collapses of temporary structures or incomplete permanent structures are a threat for the safety of persons. Based on data from Dutch Labour Inspectorate this study concluded that approximately $20 \%$ of the fatalities during construction are related to structural failures. The total number of fatalities during construction exceeds (disputable) acceptability limits in the Netherlands. Structural failures were especially influenced by motivation of employees, available equipment and procedures. Improvement is needed, which can start with an increase of safety awareness.

Keywords: structural failures, incident database, structural safety, occupational safety

\section{Introduction}

A building site is generally considered to be one of the most dangerous places to work [1]. Safety during construction is believed to be poor. A large share of the total number of structural failures already occurs during the construction phase of a structure [2].

Two recent examples within Dutch building industry are the collapse of a temporary structure during casting of a floor of the B-tower in Rotterdam in 2010 and the collapse of a roof of an extension of the FC Twente stadium in 2011.

In October 2010 the 70m high B-tower was under construction in Rotterdam. The floors of the first five storeys were constructed as precast composite plank floors, for which a temporary support structure was necessary. Scaffolding was used to create this temporary structure. On October $21^{\text {th }}$ 2010 the third floor collapsed during casting of the concrete, resulting in five injuries among the construction workers. Investigation from the Dutch Safety Board [3] revealed that a large number of stability braces was omitted in one direction, resulting in instability and collapse of the temporary structure. The vertical elements of the scaffolding had an unsupported height of approximately $11,5 \mathrm{~m}$ because of a void underneath the third floor.

In July 2011 an extension of the FC Twente stadium was built [2]. The roof structure consisted of a cantilevering steel structure with steel sheeting, which was stabilized by bracings. The roof structure was loaded by some heavy video screens, in addition to the usual loads. Because of time pressure various parties were simultaneously working on the load bearing structure, finishing structures and technical services. On July $7^{\text {th }} 2011$ part of the roof collapsed, resulting in two fatalities and nine injuries. Investigation from the Dutch Safety Board [4] revealed that the main load bearing structure was not completed and stabilized when the finishing structure was applied. In addition, the structure deviated from the intended dimensions. These aspects contributed to the collapse, according to the Dutch Safety Board. 
This paper will investigate if these cases are just one of a kind incidents, or if there might be an actual problem with structural safety during construction. Structural safety is defined as the absence of unacceptable risk associated with failure of (part of) a structure. Because the focus is on the construction phase, structural safety of both (incomplete) final structures and structural safety of temporary structures will be regarded.

The following questions related to structural safety during construction are investigated in this paper:

1. What is the actual level of unsafety during construction, due to structural failures?

2. What factors within the building process can explain this (presumably low) level of safety?

3. What measures might improve safety during construction, related to structural safety?

\section{Level of unsafety during construction}

\subsection{Risk acceptance criteria}

The first question to be answered is related to the level of unsafety during construction. Safety is defined in codes as 'a state in which the risk of harm (to persons) or damage is limited to an acceptable level' [5, art. 2.8]. This paper will primarily focus on the risk of harm to persons (individual risk). In the Netherlands the accepted probability of dying of a random unprotected person on a particular location due to hazardous goods is limited to $10^{-6}$ per year. For the individual risk of residents associated with failure of a structural element a less conservative limit of $10^{-5}$ is proposed [6]. This less conservative value might be explained by the voluntariness and personal benefits of living in a house, compared to the involuntariness of being threatened by hazardous goods.

For the individual risk as exposed to in a working environment, no value is applicable in the Netherlands. Employers are expected to provide safe working conditions, but an explanation of 'sufficiently safe' is not provided. For this paper the value of $10^{-5}$ will be used as a criterion for the individual risk, although this value is disputable. It is recommended to apply the ALARP (As Low As Reasonably Practicable) principle for risks associated with structural failure.

\subsection{Number of fatalities}

Within the Netherlands, Dutch Labour Inspectorate investigates job related accidents in various sectors. For the period 1998-2009 approximately 23.000 of these accidents have been stored in the so-called Storybuilder database [7]. This publicly available database is based on the safety concept of bow-ties [8]. In a bow-tie model the central event is the incident, in this study a structural failure. On the left side of the bow-tie the causes leading to the failure are presented. On the right side the consequences are depicted, in this case fatalities or injuries.

The bow-tie model makes uses of the hazard-barrier-target concept. A hazard is regarded as anything with the potential to cause harm. The causing of harm might be prevented by barriers, which can be regarded as physical entity (object, state or condition) that acts as an obstacle in an accident path [8]. Barriers within the building process can be regarded as good design, good construction and good use/maintenance [9]. Design, construction and use errors affect barrier performance and may cause barriers to fail. Barrier failure modes can be regarded as insufficient strength, stiffness or stability. Barrier related tasks are the tasks necessary to place the barriers and keep them in good condition. Usually, a task distinction is made in "Provide", "Use", "Monitor", and "Maintain". The tasks are influenced by Management deliveries, which are "the resources and commitments delivered by the management systems in place, through the tasks towards the 
technical system, to enforce the barriers that prevent accidents and/or reduce their consequences.'[8].

Within Storybuilder the cases related to failure of temporary or permanent structures have been selected. Examples are falls due to failure of scaffolding and impact due to contact with falling objects like beams, slabs or walls that were not adequately connected or stabilized. Table 1 shows the number of cases and fatalities related to several scenarios. It should be noted that the presented scenarios in column 1 of table 1 are not exclusively related to structural failure. However, by making sub selections within these scenarios (for instance by only selecting barrier failure modes related to insufficient strength or stability of specific elements) the accidents related to structural failure were selected. All numbers displayed in column 2 to 6 of table 1 are resulting from this selection. The numbers without brackets are related to the building sector, whereas numbers between brackets depict cases for all sections. The exact numbers are rather sensitive to selection of cases in Storybuilder and should be considered with care.

\section{Table 1. Number of cases and fatalities related to various scenarios}

\begin{tabular}{|l|l|l|l|l|l|}
\hline & $\begin{array}{l}\text { Number of } \\
\text { cases } \\
\text { building } \\
\text { sector [all } \\
\text { sectors] }\end{array}$ & $\begin{array}{l}\text { Number of } \\
\text { fatalities } \\
\text { building sector } \\
\text { [all sectors] }\end{array}$ & $\begin{array}{l}\text { Number of } \\
\text { (presumably) } \\
\text { permanent } \\
\text { injuries [all } \\
\text { sectors] }\end{array}$ & $\begin{array}{l}\text { Number of } \\
\text { (presumably) } \\
\text { non-permanent } \\
\text { injuries [all } \\
\text { sectors] }\end{array}$ & $\begin{array}{l}\text { Number of } \\
\text { unknown } \\
\text { type of } \\
\text { injuries } \\
\text { [all } \\
\text { sectors] }\end{array}$ \\
\hline $\begin{array}{l}1.1 .1 \text { Fall from } \\
\text { height - ladders \& } \\
\text { steps }\end{array}$ & $34[59]$ & $1[2]$ & $3[9]$ & $25[40]$ & $6[8]$ \\
\hline $\begin{array}{l}1.1 .2 \text { Fall from } \\
\text { height - scaffolds }\end{array}$ & $265[394]$ & $8[15]$ & $38[56]$ & $175[244]$ & $78[119]$ \\
\hline $\begin{array}{l}1.1 .3 \text { Fall from } \\
\text { height }- \\
\text { roof/floor/platform }\end{array}$ & $194[309]$ & $8[11]$ & $40[61]$ & $116[168]$ & $50[91]$ \\
\hline $\begin{array}{l}1.1 .4 \text { Fall from } \\
\text { height - hole in } \\
\text { the ground }\end{array}$ & $8[21]$ & $0[0]$ & $1[2]$ & $5[11]$ & $2[7]$ \\
\hline $\begin{array}{l}1.1 .5 .3 \text { Fall from } \\
\text { height - other }\end{array}$ & $21[39]$ & $0[0]$ & $4[7]$ & $9[20]$ & $8[12]$ \\
\hline $\begin{array}{l}1.3 \text { Fall down } \\
\text { stairs or ramp }\end{array}$ & $6[24]$ & $0[1]$ & $2[4]$ & $0[9]$ & $4[10]$ \\
\hline $\begin{array}{l}3.2 \text { Contact with } \\
\text { falling objects }- \\
\text { not cranes }\end{array}$ & $186[321]$ & $27[35]$ & $53[100]$ & $90[160]$ & $36[50]$ \\
\hline $\begin{array}{l}4 \text { Contact with } \\
\text { flying/ejected } \\
\text { objects }\end{array}$ & $2[9]$ & $0[0]$ & $1[3]$ & $1[7]$ & $0[1]$ \\
\hline $\begin{array}{l}10 \text { Buried by bulk } \\
\text { mass }\end{array}$ & $2[3]$ & $0[0]$ & $0[0]$ & $0[1]$ & $1[1]$ \\
\hline Total 1998-2009 & $718[1179]$ & $44[64]$ & $142[242]$ & $421[660]$ & $185[299]$ \\
\hline $\begin{array}{l}\text { Average number } \\
\text { per year }\end{array}$ & $60[98]$ & $3,7[5,3]$ & $11,8[20,2]$ & $35,1[55]$ & $15,4[24,9]$ \\
\hline
\end{tabular}

From table 1 it can be concluded that the scenarios with the largest number of fatal accidents are fall from height-scaffold ( 265 cases, for instance stability problems of a scaffold), fall from height roof/floor/platform (194 cases, for instance a roof that cannot bear the load of labourers during construction), and contact with falling objects- not cranes (186 cases, for instance a beam that is not connected and falls from a roof). 
According to Storybuilder on average 5,3 fatalities occurred each year in the Netherlands due to structural failures during work in all sectors (see table 1, depicted in bold). The building sector is responsible for 3,7 fatalities yearly while in the other sectors only 1,6 fatalities are counted yearly due to structural failures.

Table 2. Probability of death due to structural failures for various populations (adapted with modifications from [2]

\begin{tabular}{|l|l|l|l|}
\hline & $\begin{array}{l}\text { Population (average } \\
\text { for period 1998- } \\
\text { 2009) [10] }\end{array}$ & $\begin{array}{l}\text { Story- } \\
\text { builder } \\
\text { (per year) }\end{array}$ & $\begin{array}{l}\text { Probability of dying (per } \\
\text { year) }\end{array}$ \\
\hline $\begin{array}{l}\text { Workers in building } \\
\text { sector }\end{array}$ & 493000 & 3,7 & $\begin{array}{l}3,7 / 493000= \\
7,5^{*} 10^{-6}\end{array}$ \\
\hline $\begin{array}{l}\text { Workers in other } \\
\text { sectors }\end{array}$ & 8,3 million & 1,6 & $\begin{array}{l}1,6 / 8.3 \text { million= } \\
1,9 * 10^{-7}\end{array}$ \\
\hline
\end{tabular}

In the building industry nearly 0,5 million persons are working compared to 8,3 million in other sectors. Hence, it can be concluded that the building sector is a more dangerous place to work than the average of other sectors, with respect to the probability of death related to structural failures [2]. Similar reasoning applies for the number of injuries.

Still, the Dutch construction sector is considered relatively safe at present when compared with the European average situation in the construction sector. According to Eurostat [11], the number of fatal accidents per 100000 construction workers in the Netherlands was in 2011 only 1,7, compared to an average of 6,2 for 27 European countries. Furthermore, an improvement is observed when comparing the 2011 to the 2008 data, when the Netherlands had a rate of 9,5 compared to a European average of 7,9. However, the Eurostat data are not limited to structural failures, but encompass all accidents in the construction sector.

\subsection{Meeting risk acceptance criteria}

When the risk related to structural failures during construction is regarded, this meets the (disputable) risk acceptance criterion of $10^{-5}$. However, the total individual risk during construction ( 25 fatalities $/ 493.000=5,1 * 10^{-5}$ fatalities per year, according to Statistics Netherlands [10]) does not meet this limit. Examples of risks during construction, not related to structural failures, are: falling of persons (without structural inadequacies) and accidents due to explosions, fire, chemical exposure, car collisions etcetera.

Because the total individual risk exceeds acceptable risk criteria, attention to safety during construction needs to be improved. Although in comparison with other countries the situation in the Netherlands is currently rather good, it is necessary to work on improvement, when the goal is to reduce the risk to a level As Low As Reasonably Practicable. To provide adequate measures for improvement, it is necessary to understand the underlying factors of unsafety during construction.

\section{Explanation low level of safety}

\subsection{Results from Storybuilder}

As explained in the introduction, Storybuilder includes information on failure of management delivery systems in the analysis of accidents, which cover influencing factors on management level. Table 3 presents the failure of management deliveries for the selected accidents caused by structural failure. The numbers without brackets are related to the building sector, whereas numbers between brackets depict cases for all sectors. 
Table 3: Presence of management deliveries from Storybuilder

\begin{tabular}{|c|c|c|c|c|c|c|c|c|c|}
\hline & 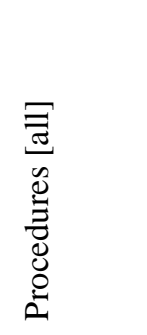 & 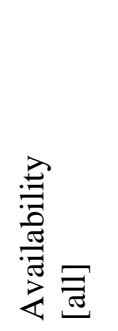 & 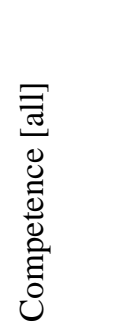 & 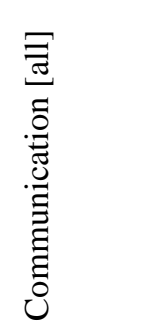 & 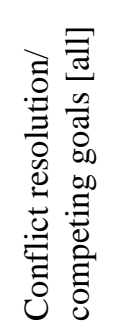 & 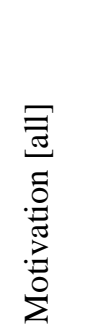 & 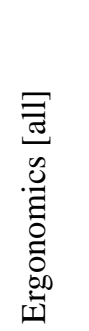 & 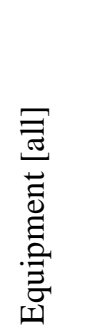 & 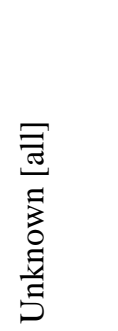 \\
\hline $\begin{array}{l}\text { 1.1.1 Fall from } \\
\text { height - ladders \& } \\
\text { steps }\end{array}$ & $4[10]$ & $2[4]$ & $1[6]$ & 3 [7] & $6[11]$ & $\begin{array}{l}20 \\
{[32]}\end{array}$ & $0[0]$ & $1[7]$ & $11[16]$ \\
\hline $\begin{array}{l}\text { 1.1.2 Fall from } \\
\text { height - scaffolds }\end{array}$ & 70 [99] & $2[5]$ & $\begin{array}{l}75 \\
{[113]}\end{array}$ & $29[45]$ & $42[59]$ & $\begin{array}{l}129 \\
{[186]}\end{array}$ & 7 [8] & $\begin{array}{l}112 \\
{[156]}\end{array}$ & $\begin{array}{l}98 \\
{[144]}\end{array}$ \\
\hline $\begin{array}{l}\text { 1.1.3 Fall from } \\
\text { height - } \\
\text { roof/floor/platform }\end{array}$ & $53[82]$ & $2[5]$ & $28[44]$ & 33 [44] & $18[25]$ & $\begin{array}{l}54 \\
{[82]}\end{array}$ & $3[5]$ & $\begin{array}{l}53 \\
{[93]}\end{array}$ & 62 [97] \\
\hline $\begin{array}{l}\text { 1.1.4 Fall from } \\
\text { height }- \text { hole in } \\
\text { the ground }\end{array}$ & $0[4]$ & $0[2]$ & $1[3]$ & 2 [3] & $1[3]$ & $0[4]$ & $0[1]$ & $3[7]$ & $2[4]$ \\
\hline $\begin{array}{l}\text { 1.1.5.3 Fall from } \\
\text { height }- \text { other }\end{array}$ & $12[18]$ & $0[0]$ & $6[6]$ & $8[10]$ & $3[3]$ & $\begin{array}{l}12 \\
{[26]}\end{array}$ & 1 [1] & 8 [14] & $5[17]$ \\
\hline $\begin{array}{l}1.3 \text { Fall down } \\
\text { stairs or ramp }\end{array}$ & $1[6]$ & $0[0]$ & 0 [3] & $1[3]$ & $4[10]$ & $1[5]$ & $0[1]$ & 2 [7] & $2[4]$ \\
\hline $\begin{array}{l}\text { 3.2 Contact with } \\
\text { falling objects - } \\
\text { not cranes }\end{array}$ & $62[113]$ & $1[3]$ & 39 [83] & $22[36]$ & $10[15]$ & $\begin{array}{l}87 \\
{[151]}\end{array}$ & $\begin{array}{l}4 \\
{[11]}\end{array}$ & $\begin{array}{l}44 \\
{[89]}\end{array}$ & $66[90]$ \\
\hline $\begin{array}{l}4 \text { Contact with } \\
\text { flying/ejected } \\
\text { objects }\end{array}$ & $0[2]$ & $0[0]$ & $2[3]$ & $0[1]$ & $0[2]$ & $1[1]$ & $0[0]$ & $0[4]$ & $2[10]$ \\
\hline $\begin{array}{l}10 \text { Buried by bulk } \\
\text { mass }\end{array}$ & $0[0]$ & $0[0]$ & $0[0]$ & $0[0]$ & $0[0]$ & $1[1]$ & $0[0]$ & $0[0]$ & $1[2]$ \\
\hline Total 1998-2009 & $\begin{array}{l}202 \\
{[334]} \\
\end{array}$ & $7[19]$ & $\begin{array}{l}152 \\
{[261]}\end{array}$ & 98 [149] & $\begin{array}{l}84 \\
{[128]}\end{array}$ & $\begin{array}{l}305 \\
{[488]}\end{array}$ & $\begin{array}{l}15 \\
{[27]} \\
\end{array}$ & $\begin{array}{l}223 \\
{[377]}\end{array}$ & $\begin{array}{l}249 \\
{[384]}\end{array}$ \\
\hline $\begin{array}{l}\text { Building sector/all } \\
\text { sectors }\end{array}$ & 0,60 & 0,37 & 0,58 & 0,66 & 0,66 & 0,63 & 0,56 & 0,59 & 0,65 \\
\hline
\end{tabular}

From this table it can be concluded that motivation (305 times), equipment (223) and procedures (202) are mentioned most often. In all of these factors management plays a role, by motivating the employees with financial or other incentives, by providing adequate equipment and by arranging useful procedures. However, employees themselves can take a responsibility by being interested in their work, being careful with the provided equipment and following up procedures when necessary or deviating from them with a profound motivation.

\subsection{Comparison national survey}

The results are complementary to the outcomes of a national survey on factors influencing structural safety. Participants from Dutch building industry (the majority of which were employed as contractor or structural engineer) were asked to rate the presence of possible influencing factors 
in both a successful and a less successful project regarding structural safety. Critical factors, with the largest difference in presence between the successful and unsuccessful projects, were communication and collaboration, risk management, control, allocation of responsibilities, safety culture and knowledge infrastructure [12]. It should be noted that risk management, control, allocation of responsibilities and safety culture were not included in the possible list of management deliveries in Storybuilder. However, communication and collaboration and lack of knowledge (knowledge infrastructure) did not appear amongst the most determining factors in Storybuilder. This might be explained by the setup of the studies. Respondents of the national survey were mainly working at larger companies (>50 employees). Usually, this type of companies is working at large scale projects were communication and coordination are more determining issues than at smaller projects. Storybuilder focuses on every job related accident, ranging from large scale projects to small scale projects.

\subsection{Explanation by national characteristics}

Another possible factor that might determine the level of safety in the building industry is the culture in the entire industry. Causes of fatalities on management level might not be limited to individual projects, but a derivation of the problems of the safety culture within the building industry. That would indicate structural problems in the entire building system, regarding safety. Two of the relevant characteristics of safety culture that were listed by Dutch Inspectorate of Housing, Spatial Planning and the Environment [13] are:

- A focus on price and time

- Increased specialisation resulting in fragmentation

A focus on price and time might result in the hiring of cheaper companies, that are not adequately equipped and that use no or suboptimal procedures. In addition, when persons are forced to deliver their work in the shortest time possible, it might reduce motivation to deliver work with high quality standards.

Increased specialisation within the building process can result in various disciplines that are not aware of the relevant issues of other disciplines. Procedures on the interaction of various disciplines are usually lacking. In combination with a focus on price and time, one might not be motivated to get familiar with the interest of the other disciplines, which is a prerequisite for trustful collaboration.

Because these characteristics are deeply rooted within Dutch building industry, the problems with management deliveries as observed from the Storybuilder database might be systemic for Dutch building industry.

\section{Measures for improvement}

To improve the problems with falling from height (scaffold, roof, floor, platform) or contact with falling objects, which were primarily influenced by the management deliveries motivation, procedures and equipment, the following measures can be considered:

1. Improve safety awareness. A reduction of safety related accidents, starts with safety awareness. When employees and clients are convinced that safety issues are relevant, this might result in a reduced focus on price and time and the availability of resources to improve safety might increase. This awareness might be stimulated by reporting failures and near misses and communicating the results of the analysis of these reports. Examples are $\mathrm{ABC}$ registration (voluntary reporting of structural incidents in the Netherlands), SCOSS 
(similar initiative in Britain) and Bouwongeval.nl (reporting of job related accidents in the Netherlands, which fulfils a legal obligation to report). Another way to improve awareness is the use of a Safety Indicator Method, which assesses various aspects of safety to make adjustments during construction possible [14]. This awareness can be activated in tool box meetings. Good examples of safety aware behaviour from management employees is key.

2. Include structural safety of unfinished structures in the contracts of structural engineers. Currently, structural engineers primarily focus on the final situation of a structure. Strength and stability during construction are regarded to be the responsibility for the contractor, although he might not be equipped to bear this responsibility.

3. Provide a 3D simulation of the construction sequence of complex structures with a check if the structure is safe during the various stages of the construction process.

4. Perform a risk analysis of non-standard temporary structures and structures that are critical during assembly. Methods are available where various risks for individuals during construction are assessed in early phases of the project [15]. This assessment stimulates the communication of knowledge on safety critical issues which can be documented in relevant procedures.

\section{Conclusion}

This paper intended to answer the following questions related to structural safety during construction:

1. What is the actual level of unsafety during construction, due to structural failures?

2. What factors within the building process can explain this (presumably low) level of safety?

3. What measures might improve safety during construction, related to structural safety?

It was concluded that the number of fatalities during construction related to structural failures is within (disputable) acceptability limits. However, the total number of fatalities during construction exceeds acceptability limits in the Netherlands.

Within the cases with fatalities related to structural failures, three management deliveries were found to be critical: motivation of employees, equipment and procedures.

It is hypothesised that a focus on price and time and fragmentation within the building industry stimulate failures of these critical management deliveries, thus, indicating systemic problems in the building industry. These factors are expected to be present in the building industries of other countries as well.

Improvement starts with safety awareness. It is recommended to include structural safety of unfinished structures in the contracts of structural engineers and to perform a risk-analysis of nonstandard temporary structures prior to the start of construction. 


\section{References}

[1] BAKHUYS ROOZEBOOM M., STAM C., VAN DER KLAUW M., NIJMAN S., YBEMA J.F., DIJKSTRA M., VENEMA A., Monitor arbeidsongevallen 2009. Hoofddorp, TNO, 2011.

[2] TERWEL K. C., BOOT W.F., NELISSE R.M.L., "Structural unsafety revealed by failure databases." Forensic Engineering (FE1): 16-26, 2014.

[3] ONDERZOEKSRAAD VOOR VEILIGHEID, Instorting verdiepingsvloer B-tower Rotterdam. Den Haag, Onderzoeksraad voor Veiligheid, 2012.

[4] ONDERZOEKSRAAD VOOR VEILIGHEID, Instorten van het dak van de aanbouw van het stadion van FC Twente, te Enschede. Den Haag, Onderzoeksraad voor Veiligheid, 2012.

[5] ISO, Quality management and quality assurance -vocabulary, ISO8402, Geneva, 1994

[6] VROUWENVELDER A. C. W. M. and SCHOLTEN N.P.M., Veiligheidsbeoordeling bestaande bouw.

Achtergrondrapport bij NEN8700. Delft, NEN/ TNO Bouw, 2008.

[7] www.RIVM.nl, accessed February 2014

[8] ANEZIRIS O., DE BAEDTS E., BAKSTEEN J., BELLAMY L.J., BLOEMHOFF A., DAMEN M., VAN EIJK V., KUIPER J.I., LEIDELMEIJER K., MUD M., MULDER S., OH J.I.H., PAPAZOGLOU I.A., POST J.G., SOL V.M., UIJT DE HAAG P.A.M., WHITEHOUSE R., The quantification of occupational risk - the development of a risk assessment model and software. Bilthoven, RIVM, 2008.

[9] PRIEMUS H. and ALE B., "Construction safety, an analysis of systems failure. The case of the multifunctional Bos \& Lommerplein estate, Amsterdam." Safety Science 48: 111-122, 2010.

[10] www.CBS.nl, accessed February 2014

[11] EUROSTAT, Fatal accidents at work by economic activity. hsw_n2_01, 2014.

[12] TERWEL K.C. and JANSEN S.J.T., "Critical factors for structural safety in the design and construction phase." Journal of performance of constructed facilities, accepted for publication.

[13] INSPECTORATE OF HOUSING, SPATIAL PLANNING AND THE ENVIRONMENT, Castle or House of Cards?, Inspectorate of Housing, Spatial Planning and the Environment, 2007.

[14] FRIJTERS A. C. P., SWUSTE P.H.J.J., VAN YPEREN H.R., How to measure safety in Construction industry? 6th International Conference on Occupational Risk Prevention. H. Sarela, A. Hale and W. Karwowski. La Coruna: Palexco: $1-12,2008$.

[15] FRIJTERS, A. C. P. and SWUSTE P.H.J.J. "Safety assessment in design and preparation phase." Safety Science 46(2): 272-281, 2008. 